\title{
Apakah Saham Berlabel Syari'ah Memenuhi Kepatuhan dan Prinsip Moral Islam? (Study Kasus: Pasar Modal Syari'ah Indonesia)
}

\section{Does the Sharia Labeled Stock Fulfill Islamic Moral Compliance and Principles? (Case Study: Indonesian Islamic Capital Market)}

\author{
Nanda Karunia Amanah ${ }^{1}$, Budi Purwanto ${ }^{1 *}$, Wita Juwita Ermawati ${ }^{2}$ \\ 1) Sekolah Pascasarjana Institut Pertanian Bogor, Kampus IPB Dramaga, Bogor 16680 \\ ${ }^{2)}$ Departemen Manajemen, Fakultas Ekonomi dan Manajemen, IPB Kampus Dramaga Bogor 16680
}

\begin{abstract}
The financial industry with the principle of shari'ah compliance has grown rapidly in almost all countries in recent years. Sharia Capital Market is an important segment of sharia financial development. The Islamic capital market must adhere to the moral principles of Islam, which are free from interest (riba), masyir (gambling) which automatically avoids things that lead to gharar (uncertainty). Islamic rules clearly forbid such conditions, so that the allocation of assets to Sharia stocks in the Islamic capital market tends to be bounded based on sharia moral principles. This study intends to evaluate the level of compliance of shariaa labeled stocks against bounded moral sharia. The method used is a measure of financial ratios based on POJK No. 35 /POJK.04/2017, linkage distance sharia compliance to default (DSCD) and the rate of compliance value for all shari'ah shares incorporated in the Indonesian Syari'ah Stock Index (ISSI). The fact is that not all shares with a syari'ah label are compliant with the existing Shari'ah moral principles.
\end{abstract}

Keywords: bounded of Islamic moral principle, Sharia Capital Market, Sharia Compliance, Sharia Stocks.

\begin{abstract}
ABSTRAK
Industri keuangan dengan asas kepatuhan syari'ah berkembang pesat hampir di seluruh negara beberapa tahun terakhir. Pasar Modal Syari'ah merupakan segmen kebutuhan penting dalam perkembangan keuangan syari'ah. Pasar modal syari'ah harus patuh terhadap prinsip moral Islam yaitu terbebas dari bunga (riba), masyir (perjudian) yang otomatis menghindarkan dari hal-hal yang mengarah pada spekulatif (ketidakpastian). Aturan Islam jelas melarang kondisi-kondisi demikian, sehingga alokasi aset terhadap saham-saham syari'ah di pasar modal syari'ah cenderung berada pada bounded berdasarkan prinsip moral syari'ah. Penelitian ini bermaksud untuk mengevaluasi tingkat kepatuhann saham-saham berlabel syari'ah terhadap bounded moral syari'ah. Metode yang digunakan adalah ukuran rasio keuangan berdasarkan POJK No. 35 /POJK.04/2017, linkage distance syari'ah compliance to default (DSCD) dan rate dari nilai kepatuhan terhadap seluruh saham syari'ah yang tergabung dalam Indeks Saham Syari'ah Indonesia (ISSI). Faktanya tidak semua saham dengan label syari'ah patuh terhadap prinsip moral syari'ah yang ada.
\end{abstract}

Kata Kunci: bounded prinsip moral Islam, Pasar Modal Syari'ah, Syari’ah Compliance, Saham Syari'ah.

*Corresponding author

Alamat email: budipurwanto@apps.ipb.ac.id 


\section{PENDAHULUAN}

Pasar modal syari'ah merupakan bagian dari kegiatan pasar modal yang memiliki karakter khusus karena dasar landasannya. Sejak sistem perbankan syari'ah muncul di Industri perbankan maka dimulailah dual banking system. Tidak seperti instrumen keuangan konvensional, gagasan fundamental industri dengan asas kepatuhan syari'ah adalah untuk menghapuskan praktik riba dan menerapkan sistem Syariah. Sharia Finance kini menjadi contoh spesifik dari sebuah pandangan yang lebih luas dari Socially Responsible Investment (SRI) (Galema et al., 2008). Indeks saham Islam mulai diperdebatkan agar lebih tangguh menghadapi krisis keuangan dibandingkan dengan indeks saham konvensional (Kim, 2018). Majid dan Kassim (2010) menemukan bahwa investor dapat memperoleh manfaat dengan diversifikasi di pasar saham syariah berlandaskan pada pengelompokan kelas ekonomi. Investasi syariah berdasarkan lima prinsip utama, yang termasuk pelarangan bunga ( $r i b a)$, pelarangan ketidakpastian berlebihan (gharar), larangan spekulasi (maysir) risiko dan pembagian kembali, dan larangan berinvestasi di industri yang 'tidak etis' (haram) (Shanmugam \& Zahari, 2009).

Boudt, Reza dan Wauters (2017), melakukan simulasi kajian pembobotan pada kapitalisasi pasar, nilai fundamental syari'ah, pembobotan terhadap risiko dan pada aset bebas risiko. Hasil penelitiannya membuktikan bahwa efek kepatuhan memberikan pengaruh signifikan bagi kinerja portofolio. Penelitian tersebut merupakan bentuk dukungan terhadap penelitian sebelumnya, Derigs dan Marzban (2009) dalam penelitiannya berhasil mempreposisi paradigma kepatuhan syari'ah tidak hanya dinilai pada tingkat individu namun juga pada tingkat manajemen portofolio. Mereka juga secara tegas mendeskripsikan tata kepatuhan yang harus dipenuhi dalam permainan investasi jika ingin dikategorikan sebagai investasi Islam. Hasilnya, menunjukkan bahwa pada strategi dasar syari' ah yang diukur dari mulai aset individu hingga manajemen aset portofolio akan memiliki kinerja yang lebih baik jika keseluruhannya memenuhi nilai kepatuhan syari'ah.

Landasan etika moral menjadi hal yang harus dipatuhi oleh indeks saham syariah. Sehingga diharapkan memberikan lebih banyak manfaat dan lebih stabil dibandingkan dengan konvensional. Dalam praktiknya, sangat sulit memisahkan pasar keuangan syariah dari pasar konvensinal di BEI yang secara otomatis menimbulkan akan linkage effect. Untuk dapat terseleksi dalam kategori indeks saham syariah tertentu harus melewati serangkaian kriteria seleksi. Sangat memungkinkan adanya perbedaan pada nilai dalam kriteria yang dibangun di setiap negara yang mengembangkan pasar modal islam, namun secara umum proses penyeleksian tersebut dibagi kedalam dua tahap yaitu penyaringan akan siklus kegiatan bisnis perusahaan dan penyaringan kriteria pada ambang rasio keuangan perusahaan. Tujuan utama dari penyaringan awal adalah untuk diskualifikasi perusahaan yang terlibat dalam kegiatan terlarang menurut syariah. Pada langkah kedua, perusahaan-perusahaan yang terlalu banyak terlibat dalam keuntungan riba dan pendapatan yang melanggar tata aturan Islam akan terdeteksi-melalui rasio utang perusahaan (El-Gamal, 2006).

Adanya batasan moral yang harus ditaati dalam portofolio Syariah memperdalam aspek penelitian ini pada karakteristik dasar Syariah dalam menentukan kinerja instrumen portofolio yang akan dibentuk. Dengan demikian rumusan masalah yang dibangun adalah bagaimana profil instrumen saham Syariah yang patuh pada batas moral Islam. Aset syariah akan mengalami preprocessing sehingga mereka dapat dikategorikan sebagai saham yang sesuai dengan aturan syariah. Secara logis tahap tersebut merupakan bagian dari upaya untuk mensterilkan preferensi aset yang membahayakan investor. Aturan yang diperlukan dalam keuangan Islam adalah mitigasi dalam hak perlindungan aset investor. Sehingga hipotesis konstruksi yang dibentuk adalah:

Jurnal Manajemen H1: Saham dengan label syariah belum tentu memenuhi-prinsip moral Islam. 


\section{METODE PENELITIAN}

\section{Data}

Data penelitian yang digunakan adalah data sekunder close price semua emiten yang terdaftar di Indeks Saham Syariah Indonesia (ISSI). Kriteria mengenai kepatuhan akan dievaluasi berdasarkan pada nomor fatwa MUI DSN: 40 / DSN-MUI /X /2003 yang juga tercantum dalam Peraturan Otoritas Jasa Keuangan Nomor 35/POJK.04/2017 tentang Kriteria dan Penerbitan Daftar Efek Syariah berdasarkan batas rasio keuangan. Data yang digunakan adalah data sekunder, dievaluasi dari Laporan Keuangan Tahunan semua perusahaan yang terdaftar yang terdaftar di BEI pada kuartal terakhir tahun 2018.

\section{Bounded Of Islamic Moral Priciple}

Landasan berdasarkan asas kepatuhan terhadap syariah membentuk suatu prinsip syari'ah dalam penerbitan produk, pembuatan kontrak syri'ah, akad transaksi dagang, serta aktivitas alokasi aset lainnya. Berdasarkan Peraturan Otoritas Jasa Keuangan Nomor 35/POJK.04/2017 tentang Kriteria dan Penerbitan Daftar Efek Syariah tentang Kriteria Dan Penerbitan Daftar Efek Syariah dengan menentukan batas rasio keuangan secara kuantitatif yang harus dipatuhi setelah steril dari aturan kualitatif adalah:

a) Total utang yang berbasis bunga dibandingkan dengan total aset tidak lebih dari 45 persen, dan

b) Total pendapatan bunga dan pendapatan tidak halal (haram) lainnya dibandingan dengan total pendapatan usaha dan pendapatan lain-lain tidak lebih dari 10 persen.

\section{HASIL DAN PEMBAHASAN}

Saham syariah yang diuji dalam penelitian ini adalah kelompok Indeks Saham Syari'ah Indonesia (ISSI). Fatwa nomor: 40/DSN-MUI/X / 2003 yang juga tercantum dalam Peraturan Otoritas Jasa Keuangan Nomor 35/POJK.04/2017 menentukan tata cara pembentukan dan nilai rasio yang harus dipatuhi agar saham dapat dikategorikan kedalam saham syari'ah. Poin pertama dari peraturan tersebut mengatur tentang batasan nilai hutang berbasis bunga dan pendapatan lain yang tidak halal dibagi dengan total aset tidak boleh melebihi 45 persen, selanjutnya akan kita disebut aspek penilaian 1 (AP1). Poin Penilaian kedua mengatur mengenai batasan pada nilai pendapatan bunga dan pendapatan lain yang tidak halal dibagi dengan total pendapatan tidak boleh lebih dari 10 persen, selanjutnya akan dsebut sebagai AP2.

Tabel 1 menyajikan nilai persentasi dari hasil rata-rata tertimbang nilai AP1 \& AP2. Hal ini akan memudahkan penafsirkan hubungan antara kepatuhan dan variabel terukur lainnya dalam portofolio. Titik Jarak ke Default dari setiap nilai pemenuhan AP1 (45 persen) dan AP2 (10 persen) akan disebut distance to default AP1 (DDAP1) dan disebut distance to default AP2 (DDAP2). DDAP1 dan DDAP2 akan menjadi indikator dalam perhitungan nilai kepatuhan terhadap bounded atas prinsip moral Islam. Rata-rata tertimbang dari AP1 \& AP2 19,32 persen, nilai ini merupakan menjadi margin dan titik default. Semakin besar jarak dari nilai titik rata-rata tertimbang menunjukkan semakin baik kepatuhannya seperti yang kita sebut Jarak Kepatuhan Syariah terhadap Default (DSCD). Terdapat 402 emiten yang terdaftar dalam kelompok indeks ISSI, dari keseluruhan anggota terdapat 365 emiten dengan Fianancial Annual Report pada last quartal 2018 yang dapat diidentifikasi nilainya. Dari keseluruhan emiten yang teridentifikasi terdapat 24 emiten yang mematuhuhi nilai bounded prinsip moral syari'ah, keseluruhan emiten yang patuh merupakan anggota dari kelompok Jakarta Islamic Index. 
Tabel 1. Daftar dan Presentasi Kepatuhan dari masing-masing Saham Syari'ah Potensial

\begin{tabular}{|c|c|c|c|c|c|c|c|c|c|}
\hline Kode & AP1 & AP2 & DDAP1 & DDAP2 & Kode & AP1 & AP2 & DDAP1 & DDAP2 \\
\hline ADRO & $19,27 \%$ & $3,20 \%$ & $25,73 \%$ & $6,80 \%$ & JSMR & $41,47 \%$ & $3,80 \%$ & $3,53 \%$ & $6,20 \%$ \\
\hline AKRA & $37,84 \%$ & $0,11 \%$ & $7,16 \%$ & $9,89 \%$ & KLBF & $10,94 \%$ & $0,47 \%$ & $34,06 \%$ & $9,53 \%$ \\
\hline ANTM & $28,20 \%$ & $3,58 \%$ & $16,80 \%$ & $6,42 \%$ & LPPF & $22,35 \%$ & $0,44 \%$ & $22,65 \%$ & $9,56 \%$ \\
\hline ASII & $38,16 \%$ & $4,84 \%$ & $6,84 \%$ & $5,16 \%$ & PGAS & $45,07 \%$ & $4,46 \%$ & $-0,07 \%$ & $5,54 \%$ \\
\hline BRPT & $44,36 \%$ & $1,10 \%$ & $0,64 \%$ & $8,90 \%$ & PTBA & $7,31 \%$ & $1,65 \%$ & $37,69 \%$ & $8,35 \%$ \\
\hline BSDE & $30,58 \%$ & $12,43 \%$ & $14,42 \%$ & $-2,43 \%$ & PTPP & $60,88 \%$ & $3,77 \%$ & $-15,88 \%$ & $6,23 \%$ \\
\hline CPIN & $24,00 \%$ & $0,71 \%$ & $21,00 \%$ & $9,29 \%$ & SCMA & $8,58 \%$ & $0,81 \%$ & $36,42 \%$ & $9,19 \%$ \\
\hline CTRA & $28,91 \%$ & $2,50 \%$ & $16,09 \%$ & $7,50 \%$ & SMGR & $30,16 \%$ & $0,65 \%$ & $14,84 \%$ & $9,35 \%$ \\
\hline EXCL & $16,37 \%$ & $0,74 \%$ & $28,63 \%$ & $9,26 \%$ & SMRA & $39,20 \%$ & $0,13 \%$ & $5,80 \%$ & $9,87 \%$ \\
\hline ICBP & $15,68 \%$ & $2,25 \%$ & $29,32 \%$ & $7,75 \%$ & TLKM & $28,91 \%$ & $0,90 \%$ & $16,09 \%$ & $9,10 \%$ \\
\hline INCO & $6,59 \%$ & $0,50 \%$ & $38,41 \%$ & $9,50 \%$ & TPLA & $34,91 \%$ & $1,49 \%$ & $10,09 \%$ & $8,51 \%$ \\
\hline INDF & $36,30 \%$ & $2,18 \%$ & $8,70 \%$ & $7,82 \%$ & UNTR & $36,00 \%$ & $1,74 \%$ & $9,00 \%$ & $8,26 \%$ \\
\hline INDY & $47,68 \%$ & $1,40 \%$ & $-2,68 \%$ & $8,60 \%$ & UNVR & $30,28 \%$ & $9,02 \%$ & $14,72 \%$ & $0,98 \%$ \\
\hline INTP & $8,39 \%$ & $0,51 \%$ & $36,61 \%$ & $9,49 \%$ & WIKA & $53,04 \%$ & $4,62 \%$ & $-8,04 \%$ & $5,38 \%$ \\
\hline ITMG & $15,63 \%$ & $2,46 \%$ & $29,37 \%$ & $7,54 \%$ & WSBP & $50,59 \%$ & $0,00 \%$ & $-5,59 \%$ & $10,00 \%$ \\
\hline & \multirow{4}{*}{$P 1$} & Average & & $29,921 \%$ & \multirow{4}{*}{\multicolumn{2}{|c|}{ AP2 }} & \multicolumn{2}{|l|}{ Average } & $2,415 \%$ \\
\hline & & Deviation & & 0,1469 & & & \multicolumn{2}{|l|}{ Deviation } & 0,027 \\
\hline & & Max & & $60,878 \%$ & & & \multicolumn{2}{|l|}{$\operatorname{Max}$} & $12,427 \%$ \\
\hline & & Min & & $6,585 \%$ & & & \multicolumn{2}{|l|}{ Min } & $0,003 \%$ \\
\hline
\end{tabular}

Sumber: Annual report, data diolah (2019)

Berdasarkan tabel 1, distribusi frekuensi rata-rata nilai AP1 (aspek kepatuhan terhadap kewajiban berbasis bunga) dengan ketentuan standardisasi tidak boleh melebihi 45 persen pada titik yang cukup aman sebesar 29,921 persen dengan standar deviasi 14,6 persen. PT PP Persero Indonesia (PTPP) memiliki poin AP1 tertinggi, yaitu 60,878 persen dengan nilai DDAP1 sebesar 15,877 poin di luar margin kepatuhan yang disebutkan. Sedangkan PT Vale Indonesia Tbk (INCO) poin kepatuhan AP1 adalah yang terbaik, yaitu 6,585 persen dengan jarak 38,415 poin di bawah margin kepatuhan yang ditetapkan. Rata-rata distribusi frekuensi berikutnya adalah pemenuhan AP2 (aspek kepatuhan pendapatan berbasis bunga) dengan ketentuan standar tidak boleh melebihi 10 persen pada 2,415 persen, dengan standar deviasi 2,7 persen. PT Bumi Serpong Damai Tbk (BSDE) memiliki poin AP2 tertinggi, yaitu 12,427 persen dengan DDAP1 2,427 poin di luar margin kepatuhan yang ditentukan. Sedangkan PT Waskita Beton Precast (WSBP) memiliki titik kepatuhan AP2 terbaik yaitu 0,003 persen dengan nilai DDAP2 9,997 poin di bawah margin kepatuhan yang telah ditentukan.

Tabel 2 menyajikan distribusi dari bentuk kuantifikasi pemenuhan dan pelanggaran terhadap bounded prinsip moral Islam yang ada di Indonesia. Rata-rata distribusi frekuensi kepatuhan terhadap poin AP1 didefinisikan dengan kuantifikasi persentasi nilai maksimal oleh INCO sebesar 85,366 persen, sedangkan PTPP memiliki persentase pelanggaran kepatuhan sebesar terbesar yaitu 35,284 persen. Sedangkan rata-rata distribusi frekuensi kepatuhan terhadap poin AP2 dengan kuantifikasi nilai maksimal oleh PT Waskita Beton Precast (WSBP) memiliki nilai persentasi AP2 terbaik yaitu 99,97 persen sedangkan BSDE memiliki persentesi pelanggaran terbesar yaitu -24,27 persen.

Jurnal Manajemen dan Organisasi (JMO),

Vol. 10 No. 2, Agustus 2019, Hal. 112-117 
Tabel 2. Presentasi Kepatuhan dari masing-masing Saham Syari'ah Potensial

\begin{tabular}{|c|c|c|c|c|c|c|c|c|c|}
\hline CODE & Risk & Return & $\begin{array}{c}\text { Compliance } \\
\text { AP1 }\end{array}$ & $\begin{array}{c}\text { Compliance } \\
\text { AP2 }\end{array}$ & CODE & Risk & Return & $\begin{array}{l}\text { Compliance } \\
\text { AP1 }\end{array}$ & $\begin{array}{c}\text { Compliance } \\
\text { AP2 }\end{array}$ \\
\hline ADRO & $6,54 \%$ & $0,35 \%$ & $57,17 \%$ & $67,97 \%$ & JSMR & $3,84 \%$ & $0,04 \%$ & $7,85 \%$ & $62,03 \%$ \\
\hline AKRA & $4,45 \%$ & $0,10 \%$ & $15,92 \%$ & $98,90 \%$ & KLBF & $3,68 \%$ & $0,10 \%$ & $75,68 \%$ & $95,33 \%$ \\
\hline ANTM & $6,12 \%$ & $0,18 \%$ & $37,34 \%$ & $64,17 \%$ & LPPF & $5,92 \%$ & $-0,26 \%$ & $50,32 \%$ & $95,55 \%$ \\
\hline ASII & $4,15 \%$ & $0,08 \%$ & $15,21 \%$ & $51,60 \%$ & PGAS & $5,66 \%$ & $-0,13 \%$ & $-0,15 \%$ & $55,40 \%$ \\
\hline BRPT & $8,20 \%$ & $1,44 \%$ & $1,43 \%$ & $88,99 \%$ & PTBA & $5,91 \%$ & $0,47 \%$ & $83,75 \%$ & $83,47 \%$ \\
\hline BSDE & $4,57 \%$ & $0,04 \%$ & $32,05 \%$ & $-24,27 \%$ & PTPP & $5,16 \%$ & $0,21 \%$ & $-35,28 \%$ & $62,29 \%$ \\
\hline CPIN & $5,63 \%$ & $0,39 \%$ & $46,68 \%$ & $92,90 \%$ & SCMA & $4,72 \%$ & $-0,10 \%$ & $80,93 \%$ & $91,94 \%$ \\
\hline CTRA & $6,00 \%$ & $0,12 \%$ & $35,75 \%$ & $75,03 \%$ & SMGR & $4,67 \%$ & $0,05 \%$ & $32,97 \%$ & $93,46 \%$ \\
\hline EXCL & $5,90 \%$ & $0,01 \%$ & $63,63 \%$ & $92,63 \%$ & SMRA & $6,02 \%$ & $0,13 \%$ & $12,90 \%$ & $98,72 \%$ \\
\hline ICBP & $3,52 \%$ & $0,30 \%$ & $65,15 \%$ & $77,50 \%$ & TLKM & $2,99 \%$ & $0,26 \%$ & $35,76 \%$ & $91,00 \%$ \\
\hline INCO & $7,11 \%$ & $0,35 \%$ & $85,37 \%$ & $95,04 \%$ & TPLA & $4,39 \%$ & $1,05 \%$ & $22,41 \%$ & $85,11 \%$ \\
\hline INDF & $3,66 \%$ & $0,06 \%$ & $19,33 \%$ & $78,18 \%$ & UNTR & $4,74 \%$ & $0,24 \%$ & $20,00 \%$ & $82,60 \%$ \\
\hline INDY & $9,97 \%$ & $0,92 \%$ & $-5,96 \%$ & $85,96 \%$ & UNVR & $3,09 \%$ & $0,26 \%$ & $32,72 \%$ & $9,79 \%$ \\
\hline INTP & $5,02 \%$ & $0,06 \%$ & $81,36 \%$ & $94,87 \%$ & WIKA & $5,02 \%$ & $0,09 \%$ & $-17,86 \%$ & $53,78 \%$ \\
\hline ITMG & $6,54 \%$ & $0,19 \%$ & $65,26 \%$ & $75,45 \%$ & WSBP & $3,13 \%$ & $-0,07 \%$ & $-12,42 \%$ & $99,97 \%$ \\
\hline \multirow{4}{*}{\multicolumn{2}{|c|}{ AP1 }} & Average & & $33,51 \%$ & \multirow{4}{*}{\multicolumn{2}{|c|}{ AP2 }} & \multicolumn{2}{|l|}{ Average } & $78,5 \%$ \\
\hline & & \multicolumn{2}{|l|}{ Deviation } & 0,33 & & & \multicolumn{2}{|l|}{ Deviation } & 0,27 \\
\hline & & \multicolumn{2}{|l|}{$\operatorname{Max}$} & $85,37 \%$ & & & \multicolumn{2}{|l|}{ Max } & $99,97 \%$ \\
\hline & & \multicolumn{2}{|l|}{ Min } & $-35,28 \%$ & & & \multicolumn{2}{|l|}{ Min } & $-24,27 \%$ \\
\hline
\end{tabular}

Sumber: Annual report, data diolah (2019)

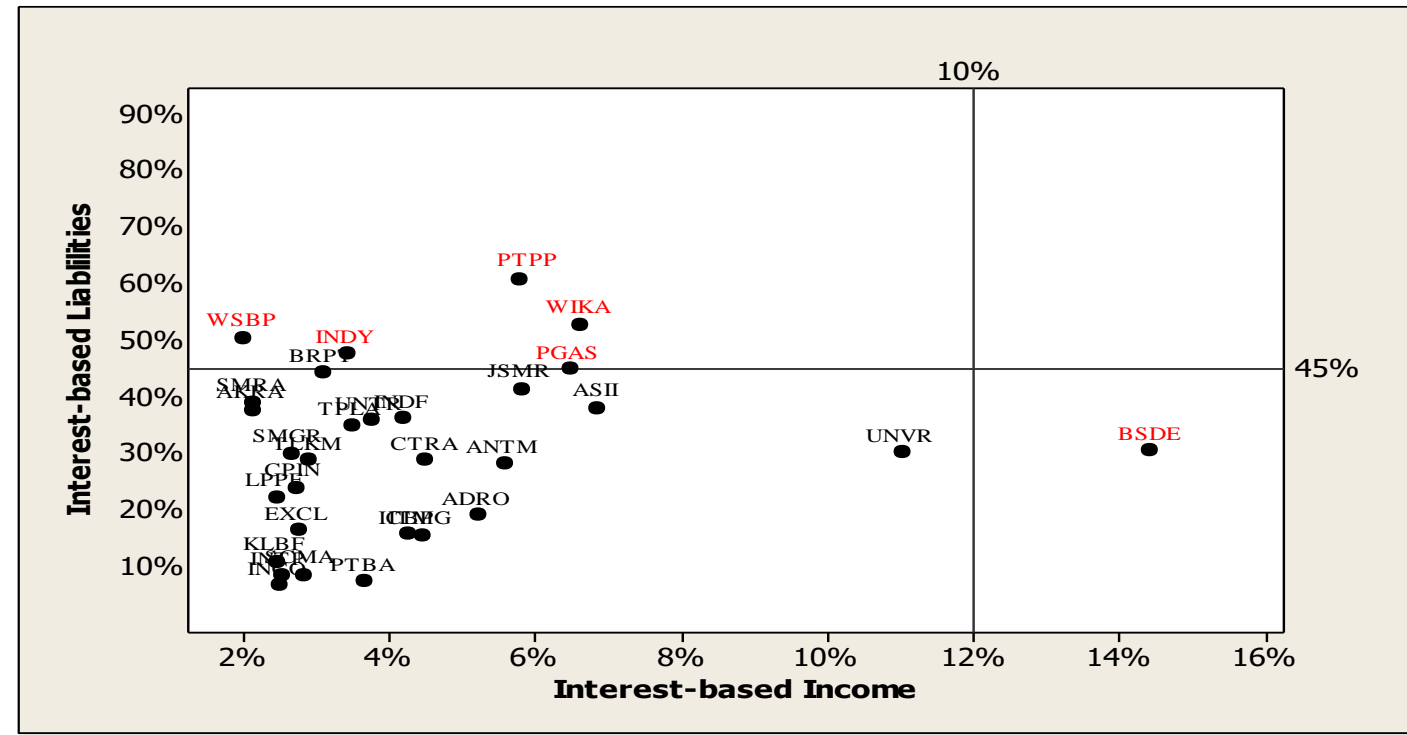

Gambar 1. Proxy Kepatuhan Kelompok Saham Syari'ah JII30

Sumbe: Financial Report $3^{\text {rd }}$ kuartal (2018); data diolah (2019)

Gambar 1. Mencerminkan proxy kepatuhan (bounded berdasarkan prinsip moral Islam) dari saham syari'ah dari kelompok JII. Jelas terlihat bahwa hanya 24 saham yang mematuhi bounded berdasarkan prinsip moral Islam. Seluruh saham syariah mematuhi aturan nilai ratsio utang bunga 
tidak lebih dari 45 persen dan pendapatan bunga tidak lebih dari 10 persen. Beberapa potensi saham Syari'ah yang belum melewati margin tingkat kepatuhan adalah WSBP, PT Indika Energy Tbk. (INDY), PTPP, PT Wijaya Karya Tbk (WIKA), PT Gas Indonesia (PGAS) dan BSDE. Tiga saham syariah dengan nilai terbaik dari batasan moral adalah PT Vale Indonesia Tbk. (INCO), Tambang Batubara Bukit Asam (Persero) Tbk. (PTBA) dan Indocement Tunggal Prakarsa Tbk. (INTP). Rasio suku bunga dan rasio pendapatan bunga dari masing-masing tiga saham syariah adalah 6,59 persen dan 0,5 persen (INCO), 7,31 persen dan 1,65 persen (PTBA) dan 8,39 persen dan 0,51 persen (INTP). Hasil penelitian ini mendukung hipotesis bahwa tidak semua saham berlabel syariah memenuhi prinsip moral syariah.

\section{KESIMPULAN}

Islamic Finance Compliance terus mendapat perhatian khusus selama dekade belakangan karena potensi yang sangat besar. Meningkatya jumlah permintaan akan produk keuangan syari'ah di pasar global merupakan indikasi bahwa Syari'ah Finance Compiliant tidak hanya diminati oleh muslim tapi sudah menjadi bagian dari solusi kebutuhan investor internasional. Meninjau dari counterpart pembentukan berdasarkan prinsip-prinsip Islam maka produk yang patuh syari'ah memiliki spesifikasi yang dibatasi oleh prinsip moral Islam. Berdasarkan tata aturan yang ada di Indonesia). Dari keseluruhan anggota ISSI sejumlah 402 emiten hanya 365 emiten dengan Fianancial Annual Report pada last quartal 2018 yang dapat diidentifikasi nilainya. Kemudian setelah dilakukan evaluasi kesesuaian terhadap tata aturan bounded prinsip moral Islam yang berlaku, terdapat hanya 24 emiten yang patuh secara prinsip. Sehingga dapat disimpulkan bahwa tidak semua saham dengan label syari'ah di Indonesia benar patuh terhadap bounded prinsip moral Islam.

\section{DAFTAR PUSTAKA}

Boudt, Reza \& Wauters (2017). Evaluating the Shariah-compliance of equity portfolios: The weighting method matters. Journal of Quantitative Strategies Finvex.

Derigs, U., \& Marzban, S. (2009). New Strategies and a new paradigm for shari'a-complaint portfolio optimization. Journal of Banking and Finance, 33, 1166-1176.

El-Gamal, M. A. (2006). Islamic finance: Law, economics, and practice. England: Cambridge University Press.

Galema, R., Plantinga, A., \& Scholtens, B. (2008). The stocks at stake: Return and risk in socially responsible investment. Journal of Banking and Finance, 32, 2646-2654.

Bae, K. H. (2018). The Portofolio management with islam equity in korea stock market. International Journal of Management and Applied Science 4.

[MUI] Majelis Ulama Indonesia. (2003). Fatwa Dewan Syariah Nasional Majelis Ulama Indonesia Nomor 40/DSN-MUI/X/2003. Jakarta: MUI.

Majid, M. S. A., \& Kassim, S. H. (2009). Impact of the 2007 US financial crisis on the emerging equity markets. International Journal of Emerging Markets, 4(4), 341-357.

[OJK] Otoritas Jasa Keuangan. (2017). Peraturan Otoritas Jasa Keuangan Nomor 35/ POJK.04/ 2017 tentang Kriteria dan Penerbitan Daftar Efek Syariah. Jakarta: OJK.

Shanmugam, B., \& Zahari, R. Z. (2009). A primer on islamic finance. Research Foundation of CFA Institute, 110-121.

Pepinsky, \& Thomas, B. (2012). Development, Social Change and Islamic Finance in Contemporary Indonesia. Journal of World Development, 41, 157-167.

Jurnal Manajemen dan Organisasi (JMO),

Vol. 10 No. 2 Agustus 2019 Hal. 112-117

Widjaja, G., \& Risnamanitis, W. (2009). Seri Pengetahuan Pasar Modal Go Public dan Go Private di Indonesia. Jakarta: Kencana. 